\title{
Review of Effective Vegetation Mapping Using the UAV (Unmanned Aerial Vehicle) Method
}

\author{
Korehisa Kaneko ${ }^{1}$, Seiich Nohara ${ }^{2}$ \\ ${ }^{1}$ Ecosystem Conservation Society-Japan, Tokyo, Japan \\ ${ }^{2}$ Center for Environmental Biology and Ecosystem Studies, National Institute for Environmental Studies, \\ Ibaraki, Japan \\ Email: kk kaneko@hotmail.com
}

Received 16 October 2014; revised 16 November 2014; accepted 10 December 2014

Copyright (C) 2014 by authors and Scientific Research Publishing Inc.

This work is licensed under the Creative Commons Attribution International License (CC BY). http://creativecommons.org/licenses/by/4.0/

(c) $\underset{\mathrm{EY}}{\mathrm{E}}$ Open Access

\section{Abstract}

We tried more precise mapping of vegetation using UAV (unmanned aerial vehicle), as a new method of creating vegetation maps, and we objected to be clearly the efficient mapping of vegetation using the UAV method by comparing vegetation maps created by analysing aerial photographs taken by a UAV and an aircraft (manned flight). The aerial photography using UAV was conducted in the Niida River estuary (the secondary river flowing into Minamisoma City in Fukushima Prefecture, Japan). The photography period was in August 2013. We analysed the aerial photographs using ArcGis 9 (Esri Japan Corporation, Tokyo, Japan). The aerial photographs of the main plant communities (Phragmites australis, Typha domingensis, and Miscanthus sacchariflorus) taken by the UAV could clearly discriminate each plant community at the $1 / 50$ scale. Moreover, it could clearly discriminate the shape of a plant at the 1/10 scale. We compared the vegetation maps by analysing the aerial photos taken by a UAV (2013 shooting) and an aircraft (2011 shooting). As a result, the vegetation map created by the UAV method could clearly discriminate community distributions. We conclude that vegetation surveys using UAV are possible and are capable of a highly precise community division in places where field reconnaissance is difficult. The UAV method is effective and will contribute to the improvement of research methods in the future; this method may reduce research costs associated with a reduction in field survey days and manpower.

\section{Keywords}

UAV (Unmanned Aerial Vehicle), Vegetation Map, High Spatial Resolution, Plant Community, Plant

\footnotetext{
"Corresponding author.
}

How to cite this paper: Kaneko, K. and Nohara, S. (2014) Review of Effective Vegetation Mapping Using the UAV (Unmanned Aerial Vehicle) Method. Journal of Geographic Information System, 6, 733-742. 


\section{Species}

\section{Introduction}

A vegetation map illustrates the geographical spread of a plant community, which is a vegetation unit. Vegetation maps provide extremely important basic information for environmental planning [1] [2]. In the past, vegetation maps have been created by skilled engineers with knowledge of vegetation. Improvements in efficiency and precision have enabled vegetation to be mapped using aerial photographs and satellite data. Mapping vegetation using satellite images may be more effective than mapping based on aerial photographs [3]. At present, the development of effective mapping and improvements in precision for creating vegetation maps are important technical issues. UAV (unmanned aerial vehicle) methods can be used in various fields and have increased the efficiency of information gathering during disasters, for remote sensing in the forest and agricultural sectors, in the management and monitoring of rivers and embankments, and in the measurement and surveying of structures and topography [4]-[7]. Moreover, UAV system was effective in identifying the present vegetation [8]-[10] [12], and is possible to generate detailed map of vegetation assemblages at the species level [11]. Experiment obtains the distribution of different vegetation species and detects invasive weeds over two cattle farms of Queensland, Australia.

[13] reported that a resolution of less than $1 \mathrm{~cm}$ is required for the precise interpretation of herbaceous plants. This resolution is the limiting factor in the remote sensing capabilities of satellites and aircraft; however, with high-resolution remote sensing using UAV methods, it is possible to discriminate herbaceous species at an individual plant level. No detailed study has yet examined the discrimination of individual plant species and plant communities by UAV.

In this report, we examined the efficient mapping of vegetation using the UAV method by comparing vegetation maps created by analysing aerial photographs taken by a UAV and an aircraft (manned flight).

\section{Study Site and Methods}

\subsection{Study Site}

The study site was in the estuarine tidal flats of the Niida River, which is a second-class river located in Minamisoma City, Fukushima Prefecture, Japan (Figure 1).

\subsection{UAV Aerial Photography Methods}

The research was conducted the aerial photography using a UAV and created a vegetation map from the aerial photographs taken by the UAV.

The UAV used a radio-controlled helicopter (MK EASY Quad XL2 1.5 CFK: Edition of HiSystems GmbH Company: Germany, Flachsmeerstr., 2, 26,802, Moormerland). The UAV was equipped with a compact digital camera (Richo GX200) mounted to a small stabilizer (Figure 2 and Figure 3). The schematic diagram of the general process of mapping using the UAV method is shown in Figure 4.

The aerial photography using an aircraft was the altitude of about $2400 \mathrm{~m}$, resolution about $24 \mathrm{~cm} / \mathrm{pixel}$, scale 1/20,000 (Photographic camera: DMC ), on the other hand, the aerial photography using UAV was the altitude of about $10 \mathrm{~m}$, resolution about $3 \mathrm{~mm} /$ pixel, scale 1/546.4 (Photographic camera: Richo NewGR). From above, the scale and resolution ratios of the aerial photograph using UAV were 36.6 and 80.0 times respectively, compared with those of aerial photography using an aircraft.

The aerial photography using UAV was conducted over a $1.5 \mathrm{~km}$ section upstream from the Niida River estuary (the secondary river flowing into Minamisoma City in Fukushima Prefecture). The photography period was in August 2013, when the vegetation is fully developed. Fixed photography points were set up in a line from the right bank to the left bank at approximately $20 \mathrm{~m}$ intervals; using the UAV, we took aerial photographs at $5 \mathrm{~m}$ above the ground surface. There were 13 line numbers in the investigated section from upstream to downstream. Each line included 8 fixed photography points, for a total of 104 points (Figure 5). 


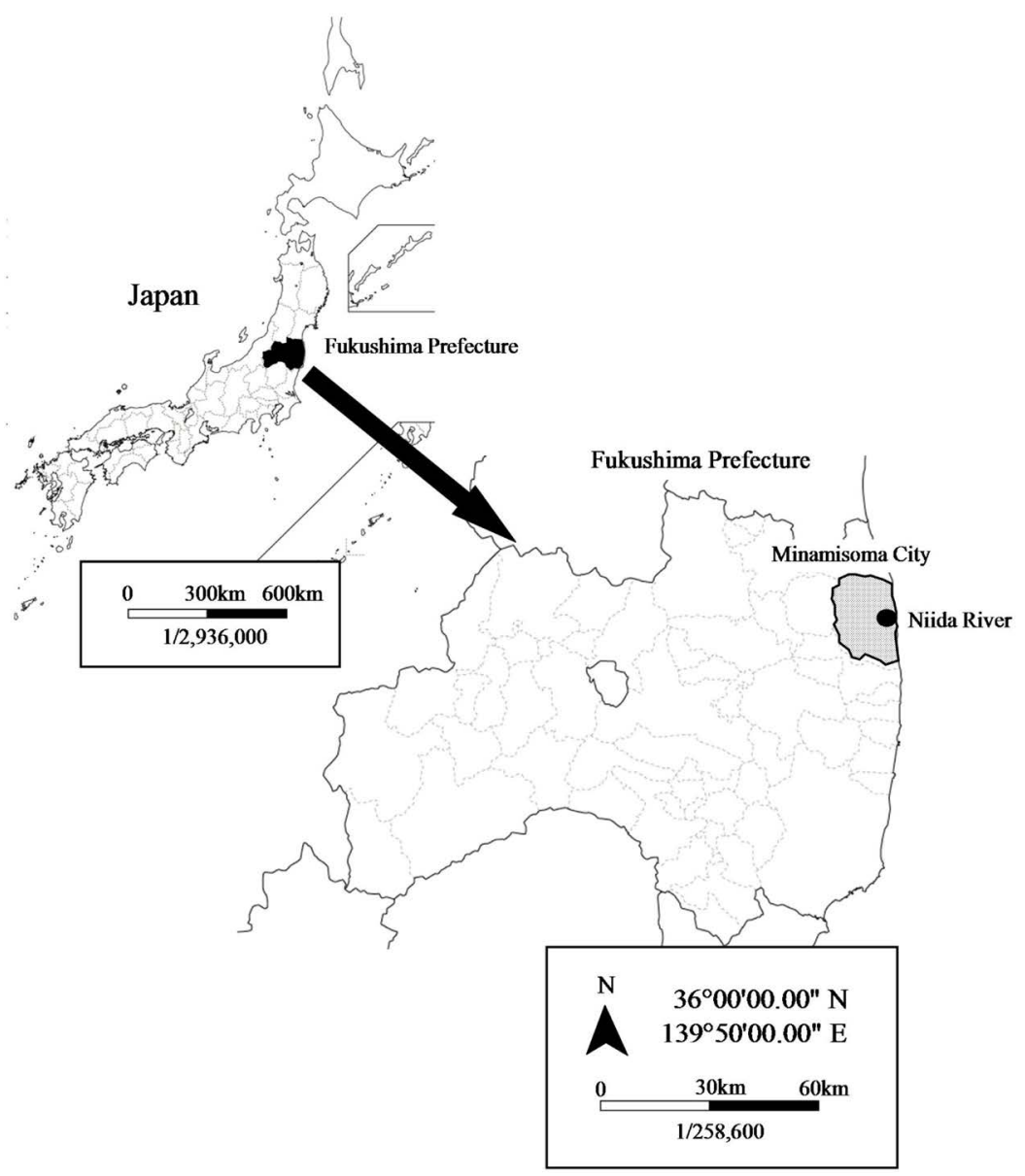

Figure 1. Study site.

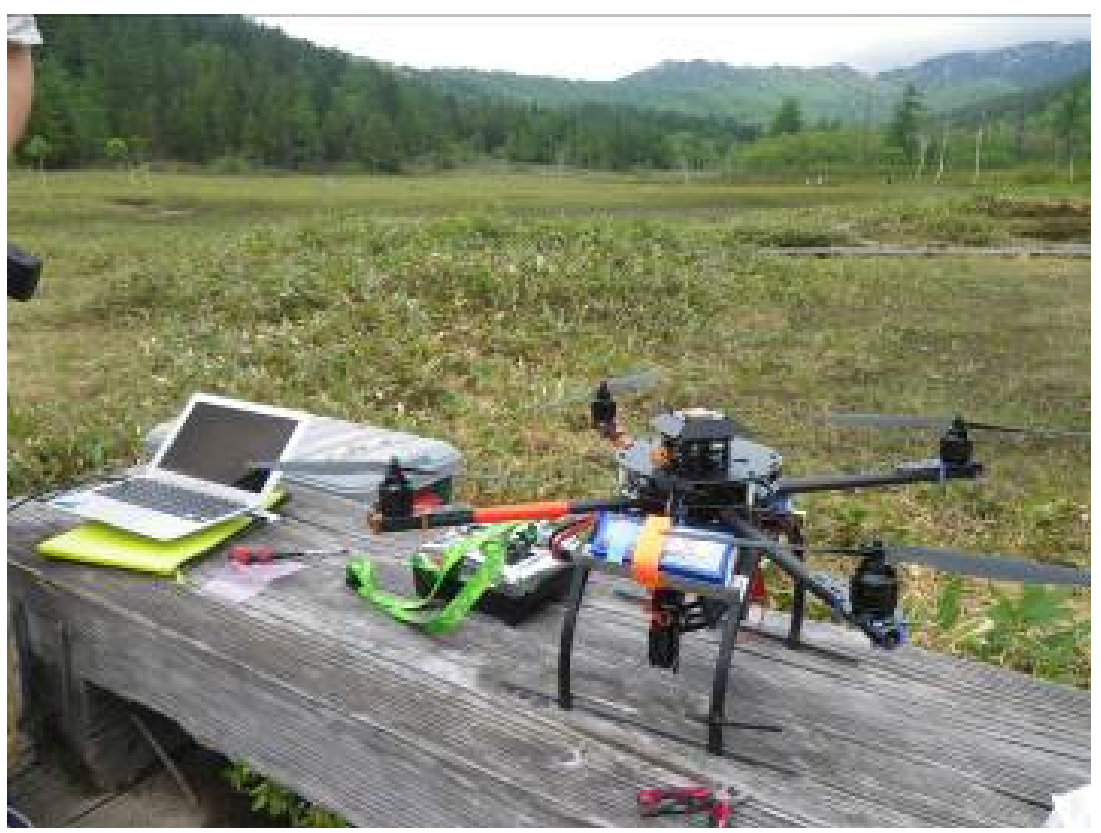

Figure 2. UAV (unmanned aerial vehicle) system. * Radio-controlled helicopter used in the study (MK EASY Okto XL2 1.5 CFK Edition of HiSystems GmbH Company). 


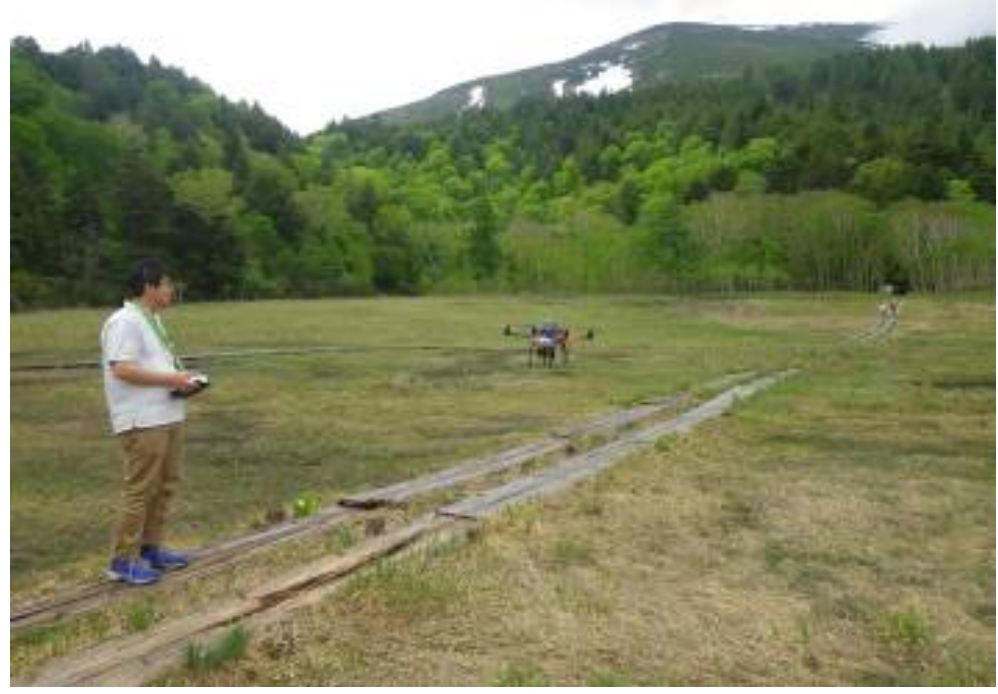

Figure 3. The landscape where aerial photographs using the UAV (unmanned aerial vehicle) were taken.

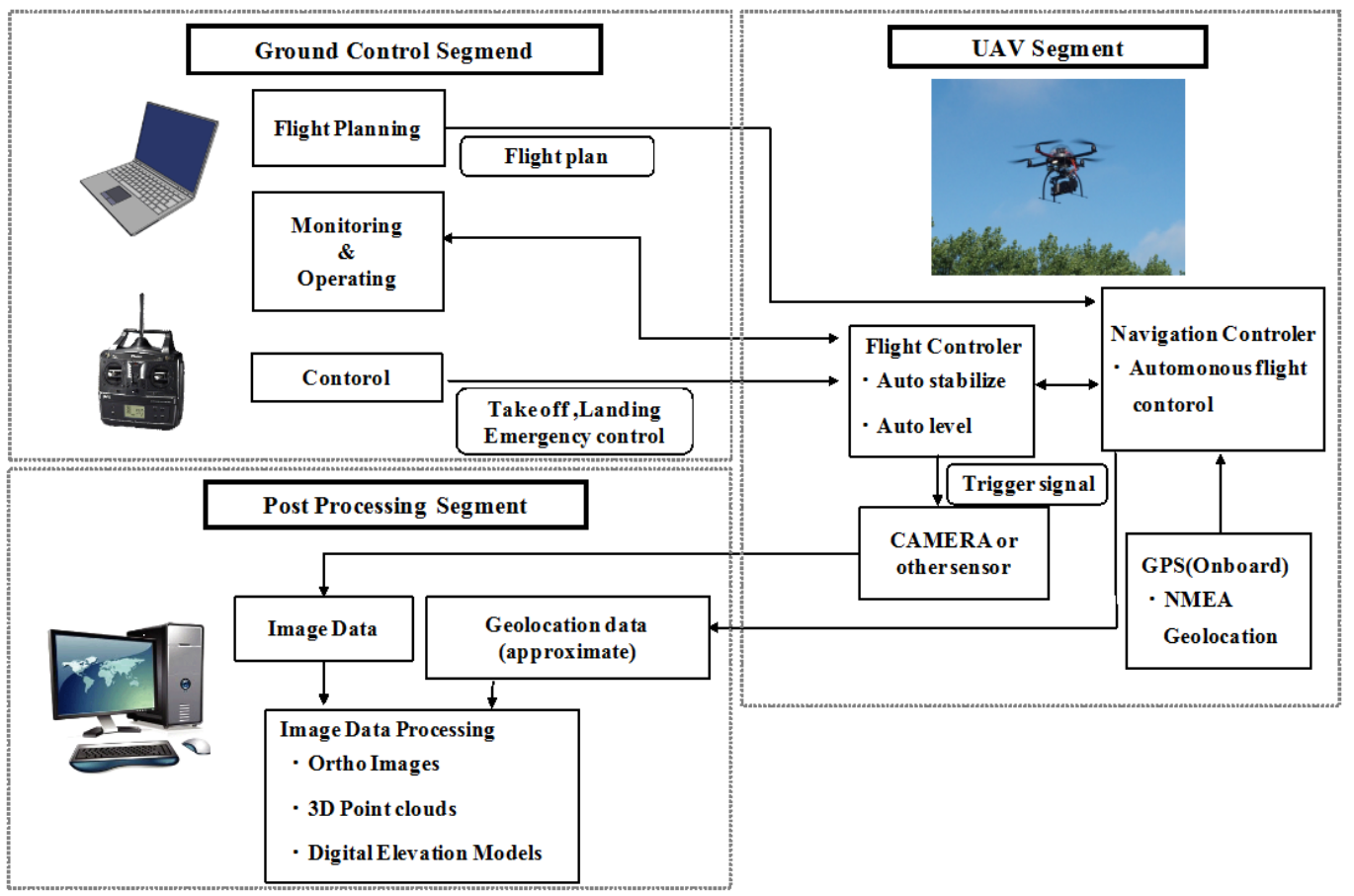

Figure 4. The schematic diagram of mapping using the UAV method.

Positioning of the captured image used GPS for navigation of the equipped UAV. GPS receiver used u-blox, Inc (LEA-6S). Positioning was conducted at $2 \mathrm{~Hz}$ (0.5 section intervals), and we were conducted the positioning of the image by matching shooting time (in seconds) that is stored in the log data (latitude, longitude and aircraft direction (camera Richo New GR) and the captured image.

\subsection{Vegetation Mapping Methods}

The vegetation map was geometrically constructed from aerial photographs, and we analysed the aerial photo- 


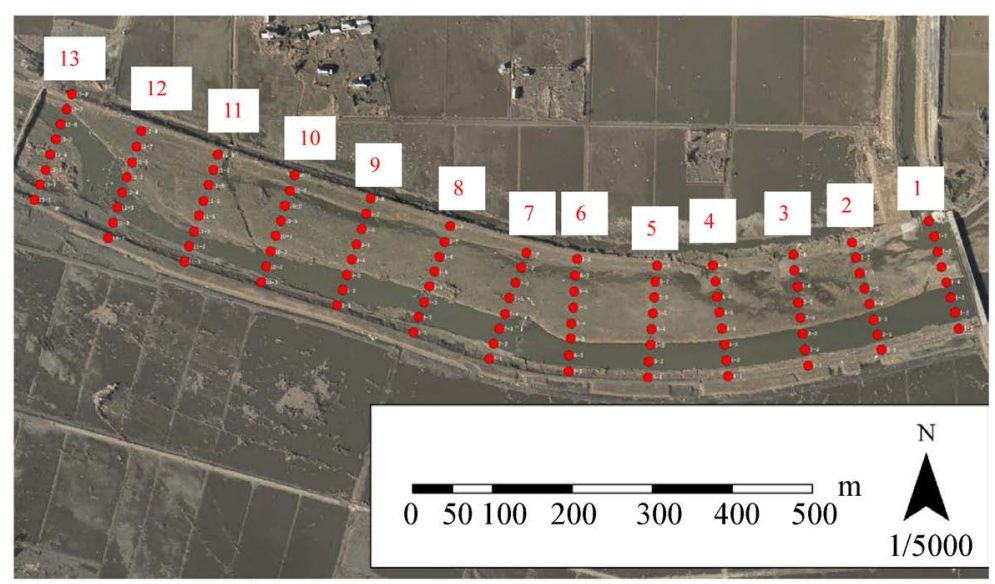

Figure 5. UAV photography lines and points (No. 1-13). ${ }^{*}$ There were 8 fixed photography points on each line.

graphs using ArcGis 9 (Esri Japan Corporation, Tokyo, Japan).

\section{Results}

In the aerial photographs of the main plant communities (Phragmites australis, Typha domingensis, and Miscanthus sacchariflorus) taken by the UAV, a clear discrimination of each plant community was possible at a scale of $1 / 50$. At a scale of $1 / 10$, it was possible to clearly confirm the shape of an individual plant (Figure 6). The borders among the plant communities and mixes of different plant species in the vicinity of the community borders could also be discriminated at this scale. An example of this resolution is the discrimination between the Phragmites australis/Scirpus yagara community and the Phragmites australis/Typha domingensis community (Figure 7).

We compared the vegetation maps that were created using aerial photos taken by the UAV (2013 shooting) and an aircraft (2011 shooting). Although plant communities in these two vegetation maps were slightly different because the shooting period and investigation year were different (Figure 8), a detailed community division was confirmed on the vegetation map created using the UAV method, and the difference in precision was remarkable. The vegetation map created using the UAV method could clearly discriminate community divisions and distributions (Figure 9).

\section{Considerations}

\section{Future Developments and Advantages of UAV Methods}

UAV provide low operational complexity and costs, compared with the classical manned aerial photogrammetry [6] [14]-[17], and remote sensing sensors placed on UAV is capacity to combine high spatial resolution and quick turnaround times providing low-cost approaches to meet the critical requirement of spatial, spectral, and temporal resolution [15].

[18] reported that, as a result of the development of a compact, lightweight, and high-resolution remote sensing system using a radio-controlled helicopter, it was possible to obtain an image with high spatial resolution (1 pixel per $1 \mathrm{~cm})$.

In our survey, plant communities of Phragmites australis and Miscanthus sacchariflorus were clearly discriminated (Figure 7). From the aerial photograph taken by the UAV, the shapes and numbers of plants were confirmed in detail, and highly precise discrimination was possible (Figure 6). We could discriminate clearly and precisely the division of many plant communities, resulting in the creation of a highly precise vegetation map (Figure 9). [13] reported that the high-spatial-resolution remote sensing using the UAV method can also be used for monitoring long-term changes. In addition, this technology can be applied to high moors, where ground-based vegetation surveys by exploration are difficult, and the reproducibility of the shooting location can be maintained. 

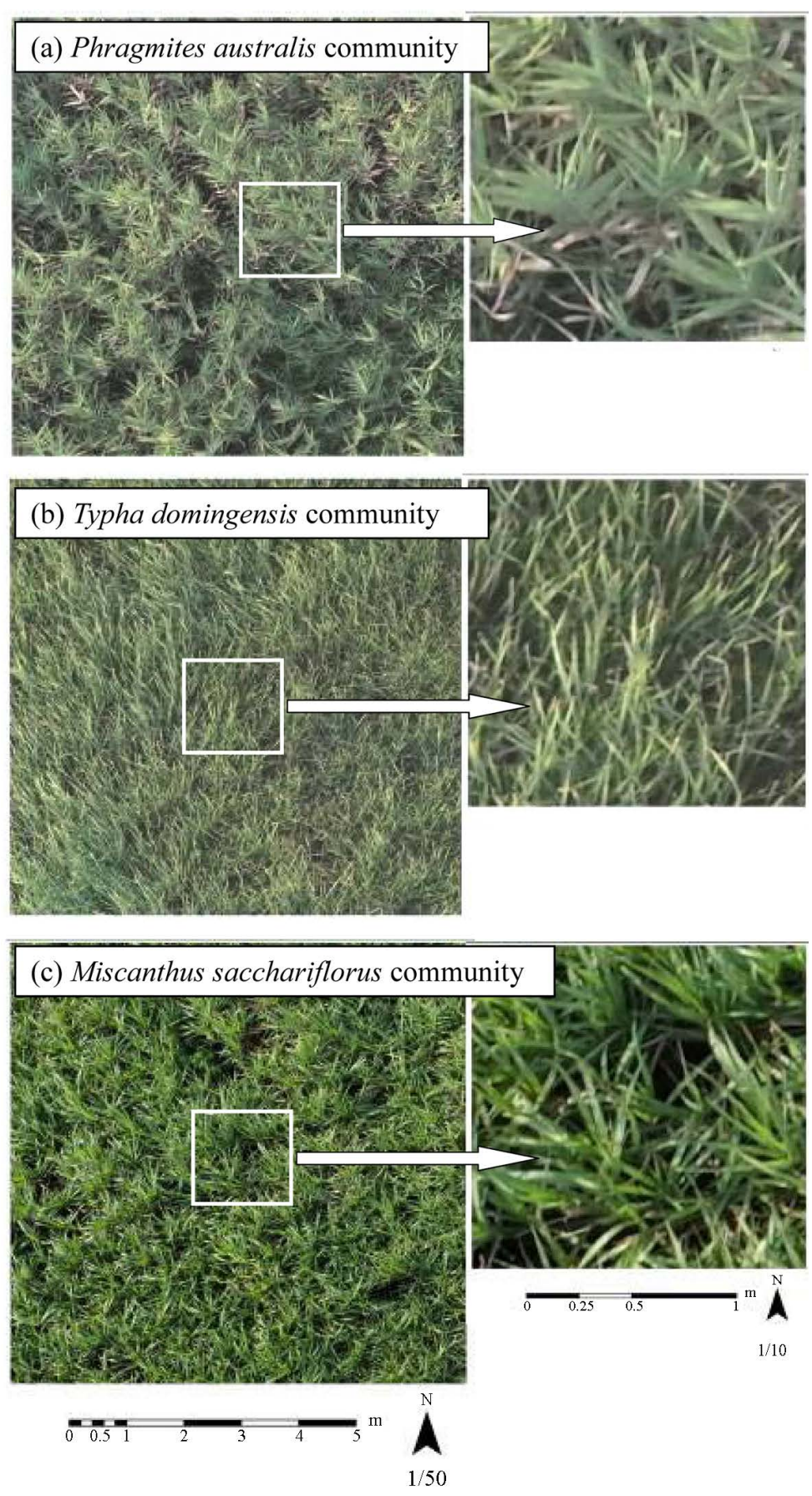

Figure 6. (a) Phragmites australis community; (b) Typha domingensis community; (c) Miscanthus sacchariflorus community photographed by UAV methods (the photo on the right is a close-up of the photo on the left).

UAV reduce the risk of access in harsh environment, still keeping high accuracy potential [19]. UAV appeared to provide a good complement to the current remote sensing platforms because of their promise of lowcost and high resolution [11].

Therefore, we conclude that vegetation surveys using UAV are possible and are capable of a highly precise community division in places where field reconnaissance is difficult. The UAV method is effective and will contribute to the improvement of research methods in the future and may reduce research costs by reducing field 

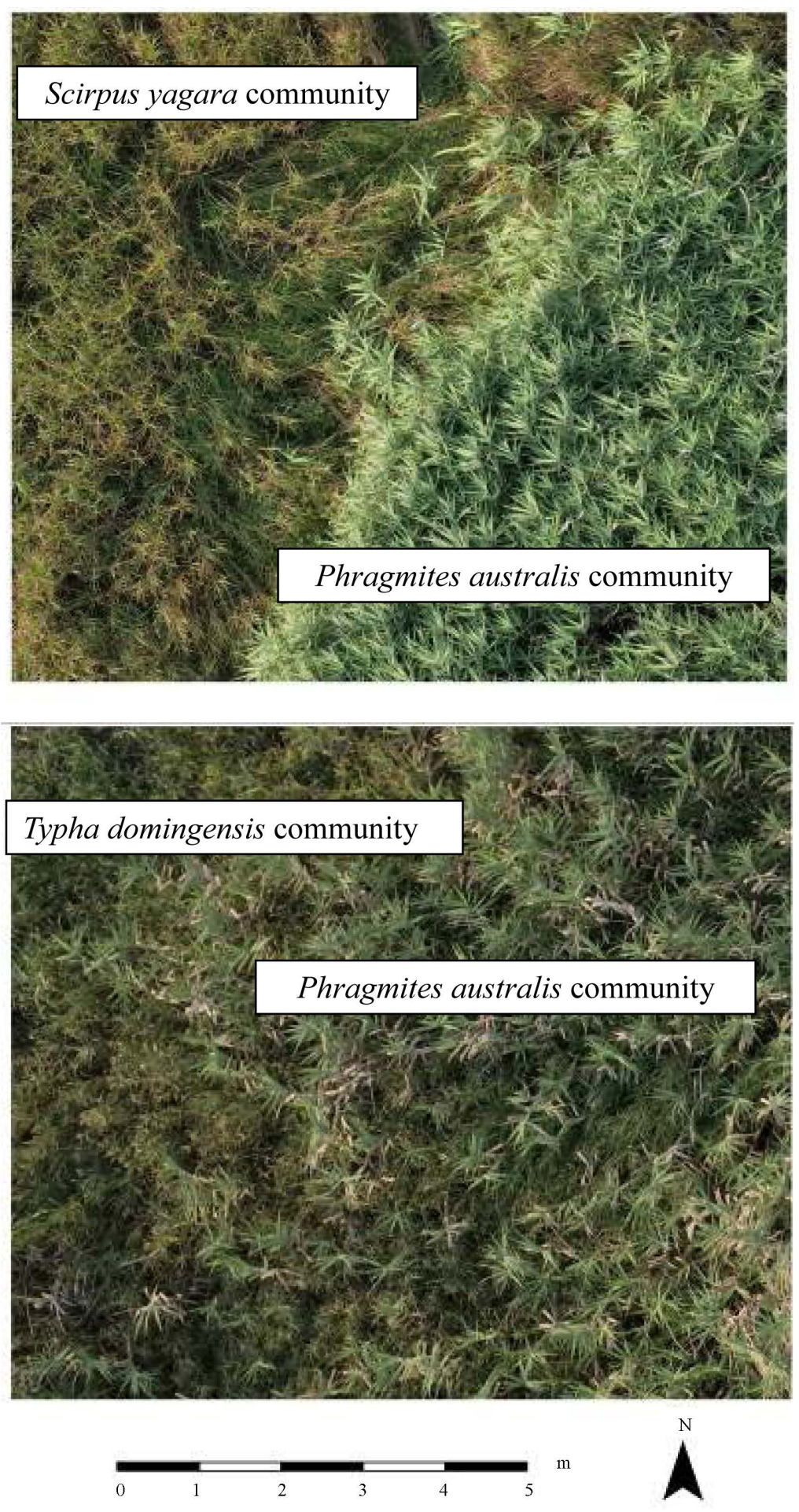

$1 / 50$

Figure 7. The vegetation division obtained by UAV methods (Top photograph: Phragmites australis community, Scirpus yagara community. Bottom photograph: Phragmites australis community, Typha domingensis community).

survey days and manpower. Additionally, we conclude that UAV methods are effective for the quantitative evaluation of vegetation community structure because the canopy height can be accurately measured. Moreover, 

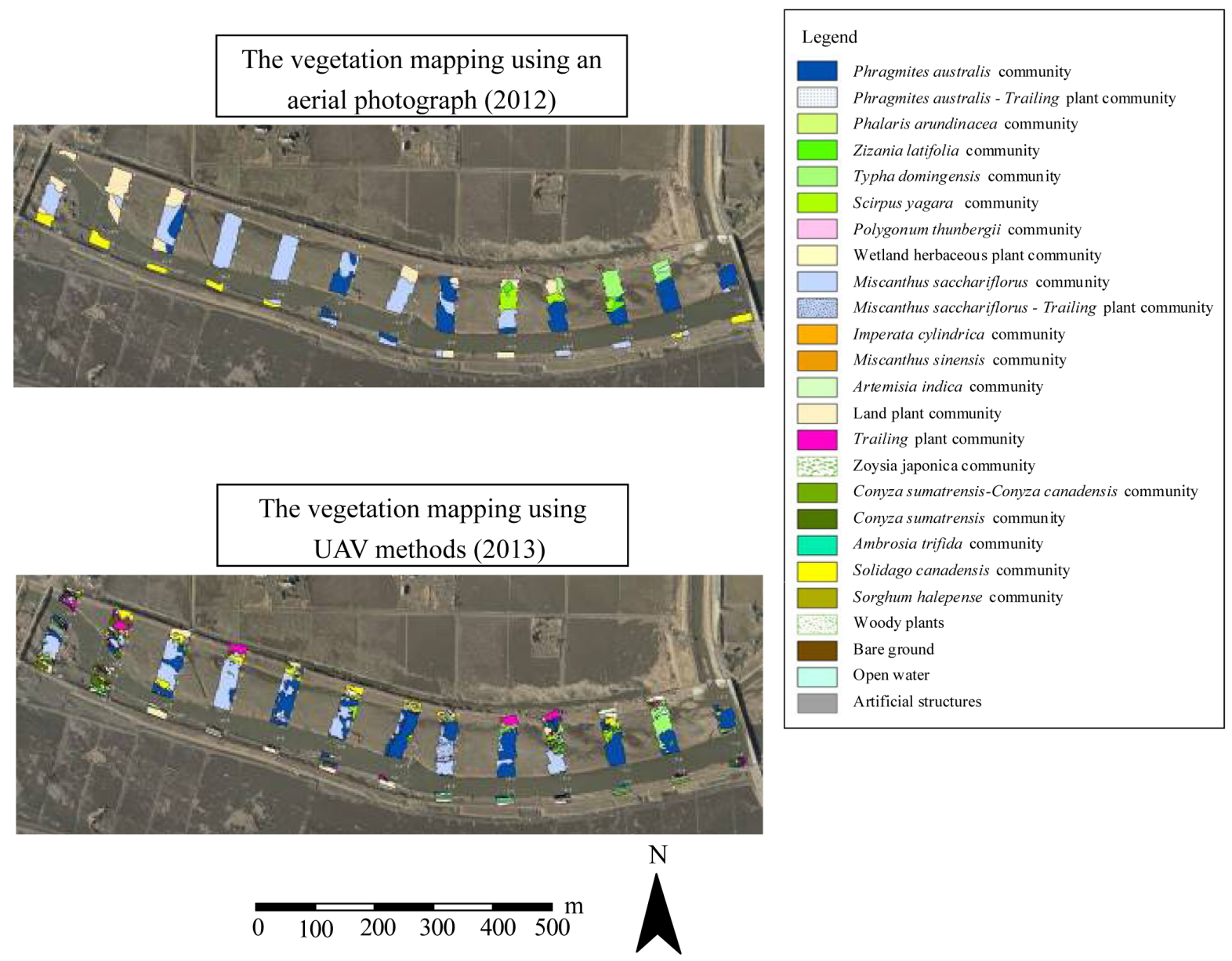

$1 / 5,500$

Figure 8. The vegetation map of the Niida River (vegetation mapping using an aerial photograph (above); vegetation mapping using UAV methods (below).

UAV methods are effective in the discrimination of indicator plant communities.

These methods can also be used for quantitative evaluations of community volume because taxonomists (in insects, amphibians, reptiles, mammals, and birds) can use UAV images to discriminate the morphologies of plants and community habitats.

\section{Conclusions}

We objected to be clear about the efficient mapping of vegetation using the UAV method. The aerial photography using UAV was conducted in the Niida River estuary (the secondary river flowing into Minamisoma City in Fukushima Prefecture, Japan). The aerial photographs of the main plant communities (Phragmites australis, Typha domingensis, and Miscanthus sacchariflorus) taken by the UAV could clearly discriminate each plant community at the $1 / 50$ scale. Moreover, it could clearly discriminate the shape of a plant at the $1 / 10$ scale. The vegetation map created by the UAV method could clearly discriminate community distributions.

We conclude that vegetation surveys using UAV are possible and are capable of a highly precise community division in places where field reconnaissance is difficult.

\section{Acknowledgements}

This research was supported by JSPS KAKENHI, Grant Number 24310025 (Studies on assessment of ecosystem functions of wetlands using environmental radioisotopes). 

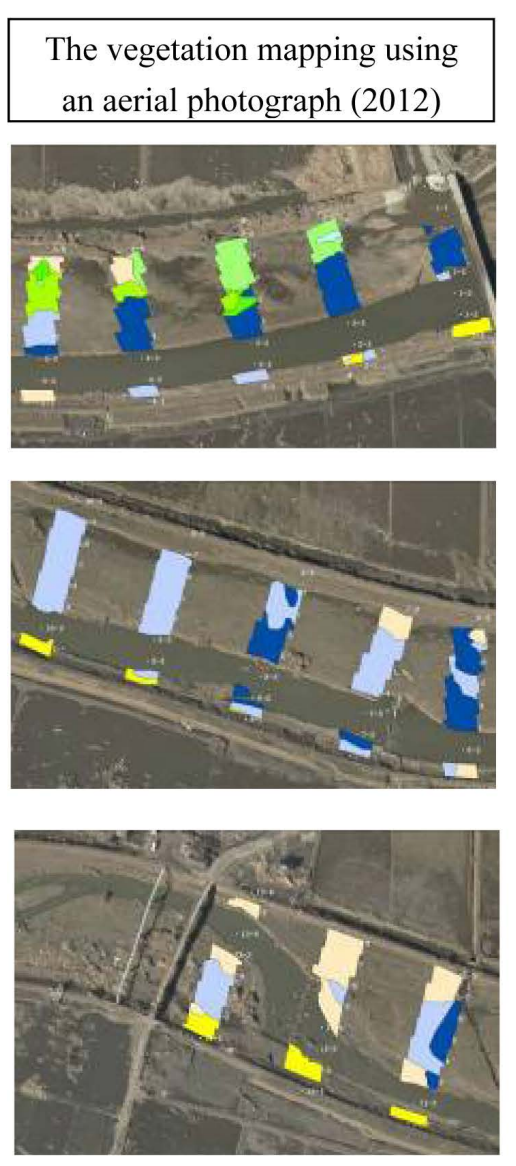
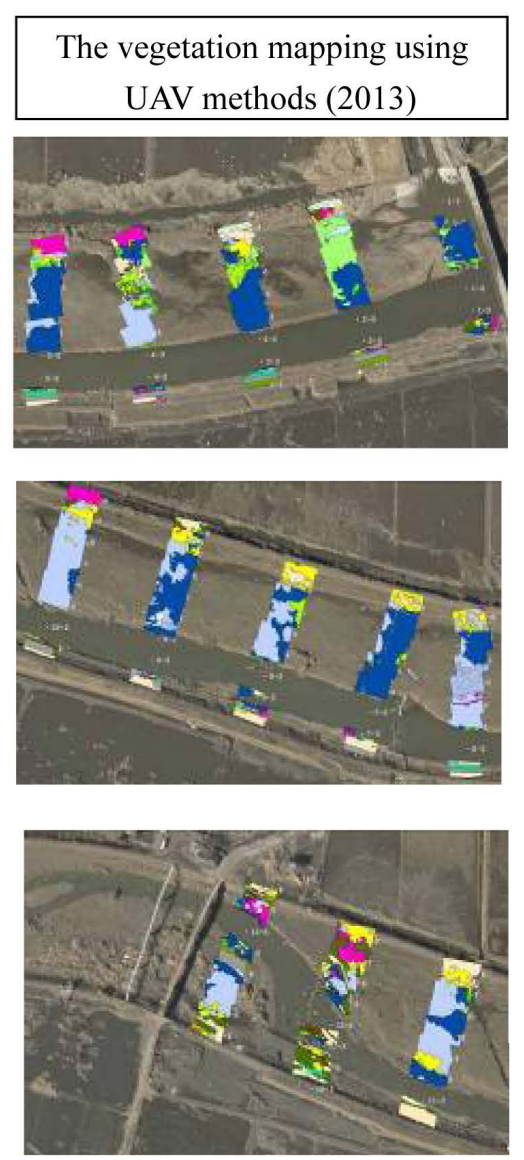

\begin{tabular}{|c|c|}
\hline \multicolumn{2}{|c|}{ Legend } \\
\hline & Phragmites australis community \\
\hline & Phragmites australis - Trailing plant community \\
\hline & Phalaris arundinacea community \\
\hline & Zizania latifolia community \\
\hline & Typha domingensis community \\
\hline & Scirpus yagara community \\
\hline & Polygonum thunbergii community \\
\hline & Wetland herbaceous plant community \\
\hline & Miscanthus sacchariflorus community \\
\hline & Miscanthus sacchariflorus - Trailing plant community \\
\hline & Imperata cylindrica community \\
\hline & Miscanthus sinensis community \\
\hline & Artemisia indica community \\
\hline & Land plant community \\
\hline & Trailing plant community \\
\hline 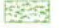 & Zoysia japonica community \\
\hline & Conyza sumatrensis-Conyza canadensis community \\
\hline & Conyza sumatrensis community \\
\hline & Ambrosia trifida community \\
\hline & Solidago canadensis community \\
\hline & Sorghum halepense community \\
\hline & Woody plants \\
\hline & Bare ground \\
\hline & Open water \\
\hline & Artificial structures \\
\hline
\end{tabular}

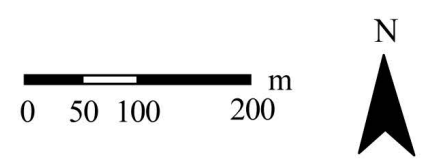

$1 / 1,500$

Figure 9. Vegetation maps using UAV methods and aerial photography (Aerial photograph, left; UAV methods, right).

Moreover, we wish to express our sincere gratitude to Mr. Hiroyuki Fukawa of Ecosystem Conservation Society Japan, who cooperated with the study.

\section{References}

[1] Environment Agency (2000) Technology Assessment of Natural Environment. Ministry of Finance Printing Bureau, Tokyo, 29-30.

[2] Organization for Landscape and Urban Green Infrastructure (2000) Ecological Network in the Urban. Gyo-sei, Tokyo, 141-142.

[3] Mathubayashi, K., Nemoto, J., Momose, H., Fujuwara, N. and Hioki, Y. (2002) Development of Vegetation Mapping Technique and Mapping Precision Using High Resolution Satellite Data. The Japanese Society of Revegetation Technology, 28, 127-131. http://dx.doi.org/10.7211/jjsrt.28.127

[4] Suzuki, T., Hashizume, T. and Suzuki, S. (2012) The Easy Building Measurement by Utilizing Small Autonomous Flying Robot (UAV). Building Construction Planning, 740, 65-69.

[5] Salami, E., Barrado, C. and Pastor, E. (2014) UAV Flight Experiments Applied to the Remote Sensing of Vegetation Area. Remote Sensing, 6, 11051-11081. http://dx.doi.org/10.3390/rs61111051

[6] Dunford, R., Michel, K., Gagnage, M., Piégay, H. and Trémelo, M.L. (2013) Potential and Constraints of Unmanned Aerial Vehicle Technology for the Characterization of Mediterranean Riparian Forest. International Journal of Remote 
Sensing, 30, 4915-4935. http://dx.doi.org/10.1080/01431160903023025

[7] Nex, F. and Remondino, F. (2013) UAV for 3D Mapping Applications: A Review. Applied Geomatics, 6, 1-15. http://dx.doi.org/10.1007/s12518-013-0120-x

[8] Arnold, T., Biasio, M.D., Fritz, A. and Leitner, R. (2013) UAV-Based Measurement of Vegetation Indices for Environmental Monitoring. 2013 Seventh International Conference on Sensing Technology, Wellington, 3-5 December 2013, 708-711.

[9] Wallace, L. (2013) Assessing the Stability of Canopy Maps Produced from UAV-LiDAR Data. Proceedings of 2013 IEEE International Geoscience and Remote Sensing Symposium (IGARSS), Melbourne, 21-26 July 2013, 3879-3882. http://dx.doi.org/10.1109/IGARSS.2013.6723679

[10] Laliberte, A.S. and Rango, A. (2009) Texture and Scale in Object-Based Analysis of Subdecimeter Resolution Unmanned Aerial Vehicle (UAV) Imagery. IEEE Transactions Geoscience and Remote Sensing, 47, 761-770. http://dx.doi.org/10.1109/TGRS.2008.2009355

[11] Strecha, C., Fletcher, A., Lechner, A., Erskine, P. and Fua, P. (2012) Developing Species specific Vegetation Maps Using Multi-Spectral Hyperspatial Imagery from Unmanned Aerial Vehicle. ISPRS Annals of the Photogrammetry, Remote Sensing and Spatial Information Sciences, I-3, XXII ISPRS Congress, 25 August-1 September 2012, Melbourne.

[12] Hung, C., Bryson, M. and Sukkarieh, S. (2012) Multi-Class Predictive Template for Tree Crown Detection. ISPRS Journal of Photogrammetry and Remote Sensing, 68, 170-183. http://dx.doi.org/10.1016/j.isprsjprs.2012.01.009

[13] Oguma, H., Usami, M., Shimazaki, H. and Ishihama, F. (2010) A High-Resolution Remote Sensing by Radio Control Helicopter and Apply to Species Discrimination of Individual Level of Wetland Herbaceous Plant. 57th Annual Conference of Ecological Society of Japan, Tokyo, 15-20 March 2010, Abstract.

[14] Eisenbeiss, H. (2004) A Mini Unmanned Aerial Vehicle (UAV): System Overview and Image Acquisition, International Workshop on Processing and Visualization Using High Resolution Imagery, Pitsanulok, 18-20 November 2004. International Archives of Photogrammetry, Remote Sensing and Spatial Information Sciences, XXXVI-5/W1.

[15] Berni, J., Zarco-Tejada, P., Suarez, L. and Fereres, E. (2009) Thermal and Narrowband Multispectral Remote Sensing for Vegetation Monitoring from an Unmanned Aerial Vehicle. IEEE Transactions on Geoscience and Remote Sensing, 47, 722-738. http://dx.doi.org/10.1109/TGRS.2008.2010457

[16] Berni, J., Zarco-Tejada, P., Suarez, L. and Fereres, E. (2014) Remote Sensing of Vegetation from UAV Platforms Using Lightweight Multispectral and Thermal Imaging Sensors. The International Archives of the Photogrammetry, Remote Sensing and Spatial Information Science, 38, 6.

[17] Jensen, A.M., Chen, Y., McKee, M., Hardy, T. and Barfuss, S.L. (2009) AggieAir-A Low-Cost Autonomous Multispectral Remote Sensing Platform: New Developments and Applications. Proceedings of 2009 IEEE International Geoscience and Remote Sensing Symposium, Cape Town, 12-17 July 2009, IV-995-IV-998.

[18] Ishihama, F., Watabe, Y. and Oguma, H. (2012) Validation of a High-Resolution, Remotely Operated Aerial RemoteSensing System for the Identification of Herbaceous Plant Species. Applied Vegetation Science, 15, 383-389. http://dx.doi.org/10.1111/j.1654-109X.2012.01184.x

[19] Remondino, F., Barazzetti, L., Nex, F., Scaioni, M. and Sarazzi, D. (2011) UAV Photogrammetry for Mapping and 3D Modelling-Current Status and Future Perspectives. International Archives of the Photogrammetry, Remote Sensing and Spatial Information Sciences, XXXVIII-I/C22 UAV-g 2011, Conference on Unmanned Aerial Vehicle in Geomatics, Zurich, 1-7. 
Scientific Research Publishing (SCIRP) is one of the largest Open Access journal publishers. It is currently publishing more than 200 open access, online, peer-reviewed journals covering a wide range of academic disciplines. SCIRP serves the worldwide academic communities and contributes to the progress and application of science with its publication.

Other selected journals from SCIRP are listed as below. Submit your manuscript to us via either submit@scirp.org or Online Submission Portal.
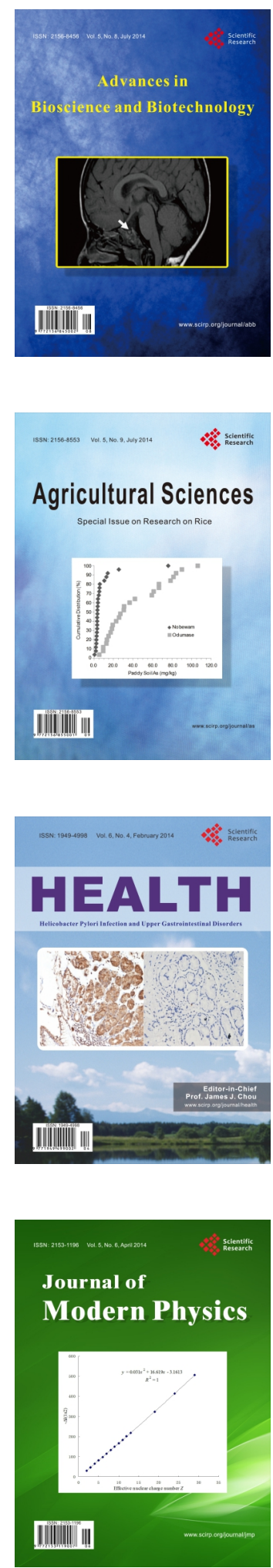
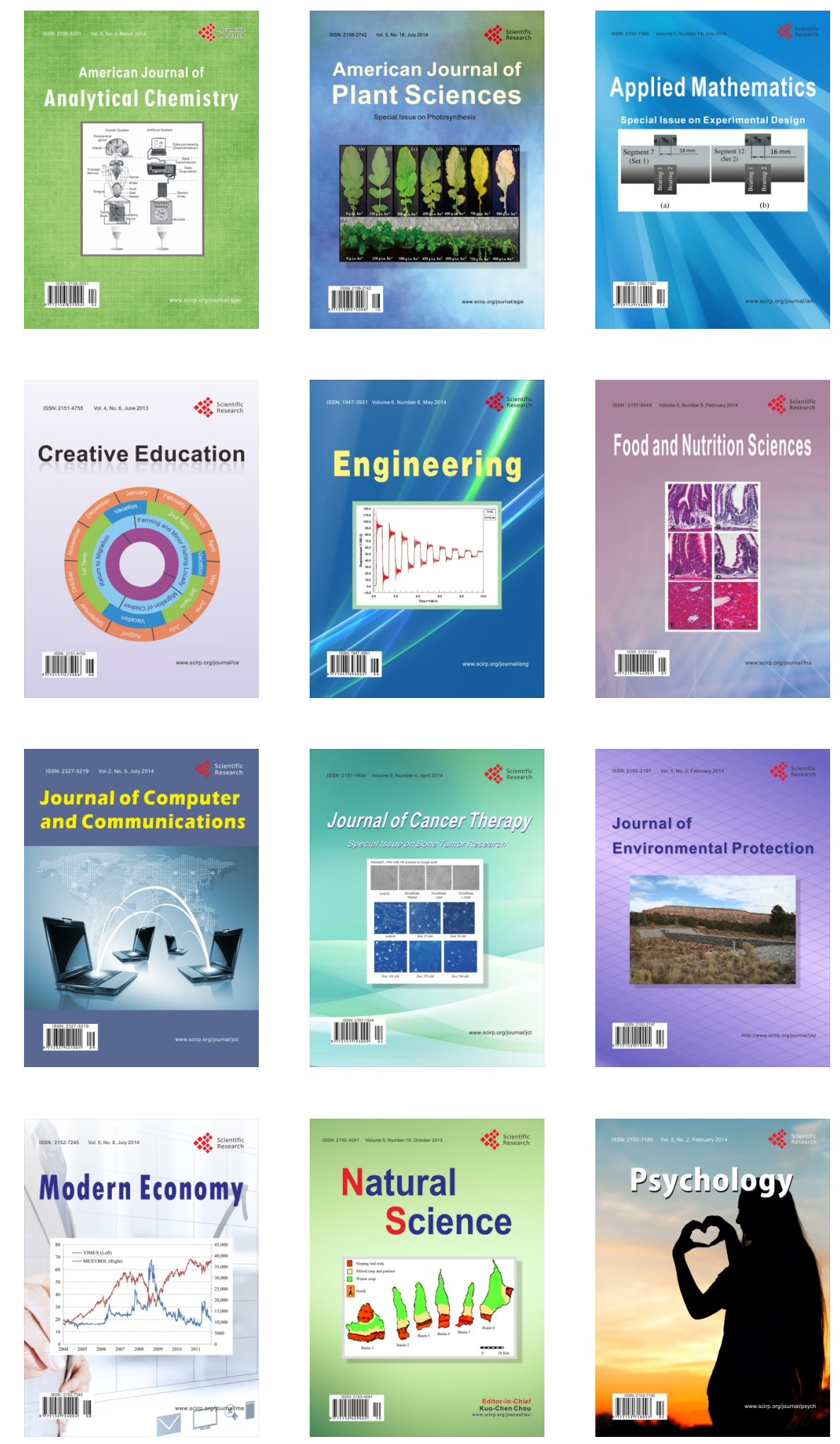